\title{
Effect of Carica Papaya L Leaf Infusion on Transporting Glucose across Small Intestine Cell Membrane of Wistar Rats Model
}

\author{
Srisathis Renganatan, ${ }^{1}$ Vycke Yunivita, ${ }^{2 *}$ Anna Martiana, ${ }^{2}$ Nida Suraya ${ }^{3}$ \\ ${ }^{1}$ Faculty of Medicine Universitas Padjadjaran, Indonesia, ${ }^{2}$ Department of Biomedical Sciences \\ Faculty of Medicine Universitas Padjadjaran, Indonesia, ${ }^{3}$ Department of Clinical Pathology Faculty \\ of Medicine Universitas Padjadjaran/Dr. Hasan Sadikin General Hospital Bandung, Indonesia
}

\section{Abstract}

Background: Carica papaya $L$ leaf is one of the common types of plant that has been used as treatment for diabetes mellitus (DM). The leaf possibly contain quercetin, which may inhibit glucose transport through cell membrane of small intestine. This study was conducted to determine the effect of Carica papaya $L$ leaf infusion on glucose transport in Wistar rat model.

Methods: A one-group pretest-posttest explorative study was designed using perfusion method. Nine male rats were fasted for 18-24 hours before dissected. A $25 \mathrm{~mL}$ glucose solution was given as early control, before Carica papaya $L$ leaf infusion treatment A $25 \mathrm{~mL}$ glucose solution was later given again after Carica papaya $L$ leaf infusion as late control. Artificial perfusion equipment had been used to maintain the back and forth flow of glucose in the small intestine. Sample was taken every 15 minutes for one hour for each treatment.

Results: Carica papaya $L$ leaf infusion did not decrease the concentration of glucose absorption significantly compared to early control. The mean absorption of glucose in early control was $85.39+4.42$ $\mathrm{mg} / \mathrm{dl}$ and during treatment was $84.51+4.20 \mathrm{mg} / \mathrm{dL}$.

Conclusions: Carica papaya $L$ leaf infusion does not have significant inhibiting effect on glucose transport across small intestine cell membrane. Further explorative study is required.

Keywords: Carica papaya L leaf, cell membrane, glucose transport, small intestine, Wistar rats.

\section{Introduction}

Diabetes mellitus (DM) is a metabolic disorder with abnormal hyperglycemia due to insulin deficiency or decrease in the biologic effectiveness of insulin. There are two different types of DM, known as type 1 and type 2 DM. Type $1 \mathrm{DM}$ related with $\beta$-cell destruction in pancreas, whereas type 2 DM due to increased insulin resistance. ${ }^{1}$ The prevalence rate for DM worldwide is estimated about $8.8 \%$ and it will increase 2 to 3 times in 2030, therefore, the number of individual with DM is projected to rise from 171 million in 2000 to 366 million in $2030 .^{2}$ The main goal of DM treatment is to decrease the glucose level in blood.

The therapy management for type 1 and type $2 \mathrm{DM}$ is quite different i.e. the therapy of type $1 \mathrm{DM}$ is insulin treatment, whereas for type 2
DM is by giving hypoglycemic agents such as sulfonylureas, biguanides or alpha-glucosidase inhibitor. ${ }^{3}$ Interestingly, there are various types of herbs that have been used as alternative treatment since olden days. ${ }^{4}$ One of the plants used in traditional treatment is Carica papaya $L$ which can be found in the tropical regions from Mexico to Panama and also in Indonesia. ${ }^{5}$ The availability of Carica papaya $L$ leaf and the related products in the market is increasing recently. The Carica papaya $L$ leaf contains phenolics such as protocatechuic acid, caffeic acid, chlorogenic acid A and B, kaemferol and quercetin.$^{6-8}$ Phenolic acids found in the Carica papaya $L$ leaf decrease the glucose uptake by blocking the glucose transporters in small intestine. ${ }^{9}$ The aim of the study was to evaluate the effects of Carica papaya $L$ leaf infusion on glucose transport across cell membrane of small intestine. 


\section{Methods}

This study was one-group pretest-posttest experimental study using perfusion method as described earlier by Sudigdo and Marsongkohadi ${ }^{10}$ conducted throughout September 2013 in Laboratory of Department of Biochemistry in Faculty of Medicine Universitas Padjadjaran. In brief, 9 healthy male Wistar rats that met inclusion criteria were included as followed; 3-4 months old and weighing 150-400 gram. Rats with body weight $>10 \%$ changes during adaptation process were excluded from the study. All rats were adapted in Department of Pharmacology Faculty of Medicine, Universitas Padjadjaran, Jatinangor for 7 days with good access to food and drink.

Carica papaya $L$ leaves were collected from Universitas Padjadjaran campus area. Around $200 \mathrm{~g}$ of Carica papaya $L$ leaves was weighed using digital scales. The Carica papaya $L$ leaves were then mixed with $200 \mathrm{~mL}$ of aquadest and heated at $90^{\circ} \mathrm{C}$ for 15 minutes. The extract of the Carica papaya $L$ leaves mix was filtered using filter paper up to $100 \mathrm{~mL}$.

Rats were food fasted around 18-24 hours prior the experiment. They were anaesthetized with $0.5 \mathrm{~mL}$ ketamin before their abdomen was dissected. Two cannulas were inserted in the intestine firmly on the distance of $10.0 \mathrm{~cm}$ from pylorus; first cannula and second cannula were apart for $25.0 \mathrm{~cm}$. The intestine was then cleaned using $0.9 \% \mathrm{NaCl}$ solution to remove the dirt by blowing Each end of the cannulas was fixed to two different test tubes. Artificial perfusion equipment was used to maintain the back and forth flow of glucose in the small intestine. All the nine rats were given three treatments, which was $25 \mathrm{~mL}$ glucose solution as the early control, $25 \mathrm{~mL}$ glucose solution with $1 \mathrm{~mL}$ Carica papaya L leaf infusion added, and $25 \mathrm{~mL}$ glucose solution as the late control. Sample was taken every 15 minutes for one hour for each treatment.

Sample obtained from the experiment was the residual concentration of glucose absorption which was measured via the deproteinization method using spectrophotometer. The concentration of glucose absorption were calculated by decreasing the concentration of standard glucose (100 mg dL-1) with the residual concentration. All subjects were terminated using diethyl ether after the treatment and experiment were finished.

As this was an explorative study, no

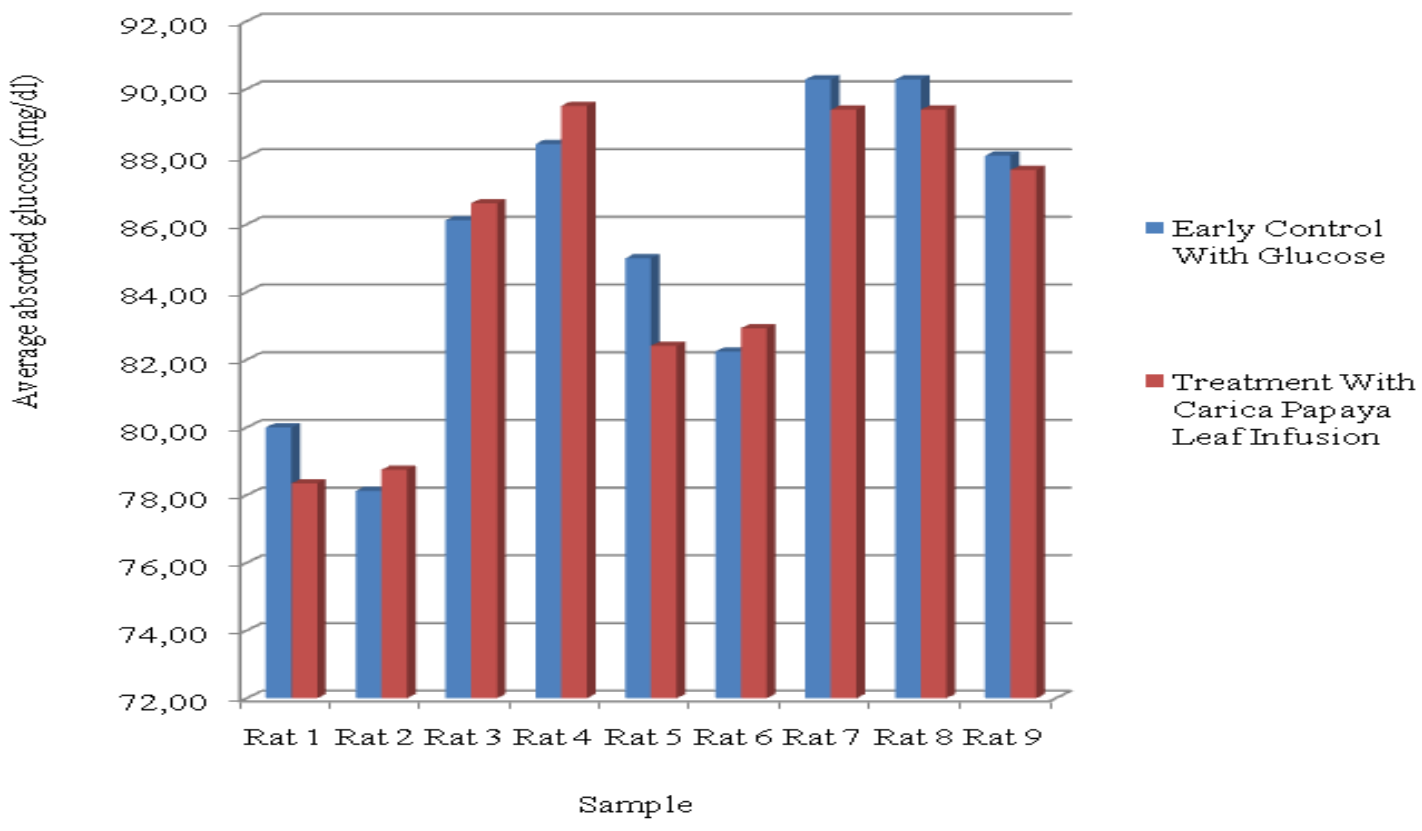

Figure 1 Glucose Absorption Concentration between Early Control and Treatment with Carica papaya $L$ leaf Infusion 
sample size calculation was performed and in this study 9 rats were assigned. Data of the concentration of glucose absorption were shown into table.

The statistical analysis was performed by comparing the treatment group with the early control group to obtain the effect of infusion and by comparing the late control group with the early control group to obtain either the effect was reversible or irreversible using one sample t-test. The reversible and irreversible effect was checked to identify whether the effect the Carica papaya $L$ leaf to the small intestine was permanent or only for the treatment period.

The protocol of the experiment performed on the laboratory in this study was approved by the Health Research Ethics Committee Faculty of Medicine Universitas Padjadjaran.

\section{Results}

The level of glucose absorption for some of the rats had shown a higher absorption rate during the treatment with Carica papaya $L$ leaf infusion when compared to the early control (Figure 1). However, the mean of glucose absorption in the early control and the treatment phase showed that Carica papaya $L$ leaf did not statistically significant decrease in glucose absorption $(85.39 \mathrm{mg} / \mathrm{dL}+4.42)$ vs. $(84.51 \mathrm{mg} / \mathrm{dL}+4.20)$ with $\mathrm{p}$ value was 0.372 .

Interestingly, the absorption level for the late control group was increased after treatment with Carica papaya $L$ leaf Infusion.
As for the second hypothesis to test whether the effect of Carica papaya $L$ leaf was reversible or irreversible by comparing early control group and late control group cannot be tested. This was because there was no significant change in glucose absorption in early control group and treatment group with Carica papaya $L$ leaf infusion (Figure 1 ).

\section{Discussion}

Our study has shown that Carica papaya $L$ leaf did not significantly inhibit glucose transport in small intestine cell membrane of rats model. This is possibly caused by the chemical properties quercetin in Carica papaya L leaf, which is believed to decrease the glucose absorption in small intestine and did not reach the level of efficacy. Besides, the preparation method of the active ingredient for the treatment (infusion, extraction, isolation), or the differences of climate, soil composition where the plant grow, and time of the harvest are possible as causes of the different study results.

Previous study has shown that Carica papaya $L$ leaf can decrease the blood glucose level. ${ }^{11}$ In this study streptozotocin (CTZ) has been given to the rats to induce diabetic rats. Furthermore, aqueous extract of Carica papaya has been administered as drinking water for one month which may lead to a decrease in blood glucose level. This effect explains as either a decrease in the rate of intestinal glucose absorption or an increase in

Table 1 The mean of Glucose Absorption Concentration of Wistar Rats Treated with Carica papaya $L$ Leaf Infusion

\begin{tabular}{lccc}
\hline & \multicolumn{3}{c}{ Absorbed Glucose (mg/dL) } \\
\cline { 2 - 4 } & Early Control & $\begin{array}{c}\text { Treatment with Carica } \\
\text { papaya L leaf Infusion }\end{array}$ & Late Control \\
\hline Rat 1 & 80.00 & 78.35 & 79.38 \\
Rat 2 & 78.13 & 78.75 & 85.38 \\
Rat 3 & 86.13 & 86.63 & 89.50 \\
Rat 4 & 88.38 & 89.50 & 90.13 \\
Rat 5 & 85.00 & 82.93 & 87.76 \\
Rat 6 & 82.24 & 89.39 & 82.76 \\
Rat 7 & 90.28 & 89.39 & 89.16 \\
Rat 8 & 90.28 & 87.61 & 89.72 \\
Rat 9 & 88.03 & $84.99+4.20$ & 89.72 \\
Mean \pm SD & $85.38+4.42$ & & $87.06+3.79$ \\
\hline
\end{tabular}


peripheral glucose utilization.

Increased catabolism of glucose due to glucose transporter 4 (GLUT4) translocation to the plasma membrane in muscle and brown adipose cells, with up-regulation of the uncoupling protein-1 in brown adipose tissue and hepatic gluconeogenesis, causes hyperinsulinemia effect or increased peripheral glucose utilization. Moreover, stimulator activity on $\beta$-cells also has been considered as the effect of aqueous extract of Carica papaya $L$ which could allow the release of more insulin. ${ }^{11}$

Other study has used alloxan to induce diabetic rats, and aqueous extracts of Carica papaya $L$ leaves shows there is a significant decrease in blood glucose level for treated group due to increased secretion of insulin of beta cells or increase of glucose uptake due to increased insulin sensitivity. ${ }^{12}$ However, in this study there is no significant decrease of glucose absorption in small intestine epithelial cell membrane, suggesting that the effect of Carica papaya $L$ leaf to lower the glucose level might be influence by some other way.

There were some limitations throughout the study. The effect of Carica papaya $L$ leaf whether it is reversible or irreversible by comparing early control and late control group cannot be tested, since there is no significant change in glucose absorption in early control group and treatment group with Carica papaya $L$ leaf infusion.

In conclusion, Carica papaya $L$ leaf infusion in our study does not have significant inhibiting effect on glucose transport across cell membrane of small intestine in Wistar rat. Different method by using alcohol extract of Carica papaya $L$ leaf is of potential benefit, and further investigation with different routes of administration are needed.

\section{References}

1. Maharani U, German M. Pancreatic hormones and diabetes mellitus. In: Gardner D, Shoback D, editors. Greenspan's basic and clinical endocrinology. 8th ed. San Francisco: McGraw Hill; 2007. p. 661-747.

2. PERKENI. Konsensus Pengendalian dan Pencegahan Diabetes Mellitus Tipe 2 di
Indonesia. $8^{\text {th }}$ ed. Jakarta: PERKENI; 2015. p. 1-82

3. Molina PE. Endocrine physiology. $2^{\text {nd }}$ ed. New York: McGraw-Hill Medical; 2006. p. 173-8.

4. Modak M, Dixit P, Londhe J, Ghaskadbi S, Devasagayam. Indian herbs and herbal drugs used for the treatment of diabetes. J Clin Biochem Nutr. 2007;40(3):163-73.

5. Indran M, Mahmood AA, Kuppusamy UR. Protective effect of Carica papaya L leaf extract against alcohol induced acute gastric damage and blood oxidative stress in rats. West Indian Med J.2008;57(4):323-6.

6. Lim TK. Edible medicinal and nonmedicinal Plants. Carica Papaya. $2^{\text {nd }}$ ed. New York: Springer;2012. p. 693-717.

7. Canin A, Alesiani D, D'Arcangelo G, Tagliatesta P. Gas chromatographymass spectrometry analysis of phenoliccompounds from Carica papaya $\mathrm{L}$. leaf . J Food Comp Anal. 2007;20(7):580 90.

8. Abdullah NR., Afzan A, Halim SZ, Rashid BA, Semail RH, Abdullah N, et al. Repeated dose 28-days oral toxicity study of Carica papaya L. leaf extract in Sprague Dawley Rats. Molecules. 2012;17(4):4326-42.

9. Gray N. Phenolic compounds may regulate glucose transport: Study. 2010; [cited 2013 February 24] Available from: http://www. drpressman.com/phenolic-compoundsmay-regulate-glucose-transport-study/.

10. Marsongkohadi, Sudigdo. Effect of herbal leaf infusion on transporting glucose across small intestine cell membrane of Wistar rat [dissertation]. Bandung: Institut Teknologi Bandung;1988.

11. Juarez-Rojop IE, Daaz-Zagoya JC, BleCastillo JL, Miranda-Osorio PH, CastellRodraguez AsE, Tovilla-Zarate CA, et al. Hypoglycemic effect of Carica papaya leaves in streptozotocin-induced diabetic rats. BMC Complement Altern Med. 2012;12(1):236.

12. Maniyar Y, Bhixavatimath P. Antihyperglycemic and hypolipidemic activities of aqueous extract of Carica papaya Linn. leaves in alloxan-induced diabetic rats. J Ayurveda Integr Med. 2012;3(2):70-4. 